\title{
Characterization Analysis of Textured and Diffused Monocrystalline Silicon Wafer
}

\author{
Asrafusjaman Rubel \\ M. A. Kabir \\ Masud Rana \\ Ariful Islam
}

Md. Shawkut Ali Khan

Department of Mechanical Engineering, City University, Bangladesh

\section{Doi:10.19044/esj.2021.v17n17p125}

Submitted: 28 December 2020

Accepted: 23 March 2021

Published: 31 May 2021
Copyright 2021 Author(s)

Under Creative Commons BY-NC-ND

4.0 OPEN ACCESS

Cite As:

Rubel A., Kabir M.A., Rana M., Islam A. \& Ali Khan M.S. (2021). Characterization Analysis of Textured and Diffused Monocrystalline Silicon Wafer. European Scientific Journal, ESJ, 17(17), 125. https://doi.org/10.19044/esj.2021.v17n17p125

\begin{abstract}
This paper focuses on examining the characteristic analysis of the textured and diffused silicon wafer. Characterization performance of the textured and diffused wafer using surface reflection method, sheet resistance method, SEM, and surface photovoltage method is examined. From the SRM result, it is observed that the reflection of the textured wafer is lower than the raw wafer. This means that the textured wafer forms the pyramid structure, which was measured by SEM. Sheet resistance measures the resistivity of the raw wafer and after phosphorous diffusion into the p-type silicon, the wafer are $2.3 \Omega$-cm and $0.80 \Omega$-cm respectively. From the sheet resistance results, it is observed that the phosphorus doping is properly done. The Surface Photovoltage (SPV) result shows that minority carrier diffusion length and lifetime for a solar cell is $86.4 \mu \mathrm{m}$ and $2.8 \mu \mathrm{sec}$ respectively.
\end{abstract}

Keywords: Characterization, monocrystalline silicon solar cell, surface texturing, phosphorus diffusion 


\section{Introduction}

Monocrystalline PV cells belong to the first generation, which is also popular and one of the oldest technologies of PV cells. These are made from a single crystal ingot of highly pure molten silicon usually crystalline silicon (c-Si). These PV cells were developed in the 1950s as first generation solar cells. Monocrystalline PV cells use wafers, of about $0.3 \mathrm{~mm}$ thick, sawn from a Si ingot of single crystal silicon made by using Czochralski process that was discovered in 1916. It is a method of crystal growth used to obtain single crystals of semiconductors, metals, and salts with the most important application in the growth of large cylindrical ingots of single-crystal silicon. Thus, monocrystalline cells are more expensive to manufacture (Salahuddin, 2017).

In the photovoltaic industry, crystalline silicon solar cells have more than $85 \%$ of the market share of all solar cells. Compared to multi-crystalline silicon (mc-Si) with about $45 \%$ of the market share, monocrystalline silicon ingot wafers are more expensive and are extensively used in solar-cell fabrication due to their good crystalline quality for high conversion efficiency. However, mc-Si wafers are considered as the most promising material type capable of achieving low-cost solar-cell manufactures (Muller et al., 2011; Elghitani \& Martinuzzi, 1989; Chen, 2001; Narayanan \& Wohlgemuth, 1994). In the past, reducing cost and getting high efficacy was possible by using thickness such as optical reflectance, thermal expansion (diffusion process), and the process of Si wafer (Suhaila, 2013).

In this study, the optical reflectance reduced by texturing process which was used in alkaline-based chemical solution $(\mathrm{KOH})$, while diffusion process was used in liquid phosphorus Oxychloride $\left(\mathrm{POCl}_{3}\right)$. This formed an n-type emitter to the p-type wafer. The performance of the textured and diffused wafer is measured by characterization analysis. This study mainly discusses the characterization analysis of the textured and diffused wafer.

\section{Experimental Work}

The fabrication process of silicon solar cell starts with a p-type monocrystalline silicon wafer with a square shape that is $150 \times 150 \mathrm{~mm}^{2}$ in size and $200 \mu \mathrm{m}$ in thickness. Silicon wafers are cut with a saw, which leaves dust, lubricate oil, etc. on the wafers. For this reason, Si wafers require cleaning.

The cleaning process was done in two stages. In the first stage, a chemical solution of sodium hydroxide and DI water $\left(\mathrm{NaOH}: \mathrm{H}_{2} \mathrm{O}\right)$ at $1 \mathrm{gm}$ was used. Thereafter, $10 \mathrm{ml}$ respective volume ratio at the temperature of $70^{\circ} \mathrm{C}$ was used for 10 minutes in order to remove the organic contaminants from $\mathrm{Si}$ wafer. In the next stage, a solution of $\mathrm{HF}: \mathrm{H}_{2} \mathrm{O}$ at $1 \mathrm{ml}: 50 \mathrm{ml}$ respective volume ratio was used in order to remove ionic contaminants and native oxide layer. After the cleaning process, texturing on the solar cell was done to reduce 
reflection and enhance light absorption. The surface texturing required an alkaline-based chemical solution of $\mathrm{KOH}$ (Potassium Hydroxide): IPA (Isopropyl Alcohol): $\mathrm{H}_{2} \mathrm{O}$ (DI-water) at $1 \mathrm{gram}: 5 \mathrm{ml}: 125 \mathrm{ml}$ respective volume ratio at the temperature of $70{ }^{\circ} \mathrm{C}$ for 20 minutes. The next stage after the texturing process is the phosphorus diffusion process. Phosphorus diffusion process is the most important feature of a silicon cell, and it forms p-n junction. This diffusion furnace was used in a liquid Phosphorus Oxychloride $\left(\mathrm{POCl}_{3}\right)$ source for emitter formation at the temperature of $600{ }^{\circ} \mathrm{C}$ to $875{ }^{\circ} \mathrm{C}$ for 10 minutes.

\section{Results and Discussions}

Characterization methods were used to assist with the performance analysis of textured and diffused wafer in BAEC Laboratory. Textured wafer characterization analysis was carried out using Surface Reflectance Method (SRM) and Scanning Electron Microscope (SEM) methods, while diffused wafer characterization analysis was carried out by Sheet Resistance Measurement (Four Point Probe Measurement) and SPV (Surface Photo voltage).

\section{Surface Reflectance Method}

The reflectance measurement system is used to measure the surface reflection of planar Si wafer and textured $\mathrm{Si}$ wafer. Reflectance measurement is performed before the saw removal process, and this is followed by the texturing process. Finally, the results of these two were compared to the reflectance of a standard mirror. The lowest reflectance indicates the best texturing regarding its ability to absorb more lights. Measurement system is based on a mini monochromator driven with a stepper motor to vary wavelengths in the $\sim 400-1200$-nm spectral range.

In Figure 1, it is observed that the maximum surface reflectance of raw silicon wafer at the wavelength of $1,000 \mathrm{~nm}$ is $3.5391465 \mathrm{mv}$ and the same wavelength of the maximum texturing reflectance of the silicon wafer is $1.7659784 \mathrm{mv}$. The difference between the maximum reflectance of the raw wafer and texturing wafer is $1.614222 \mathrm{mv}$ in the same range.

From the graph, it is also observed that the surface reflectance of texturing silicon wafer is significantly lower than the raw reflectance of silicon wafer. Reflectance is lower in texturing solar cell wafer with high efficiency of the solar cell. 


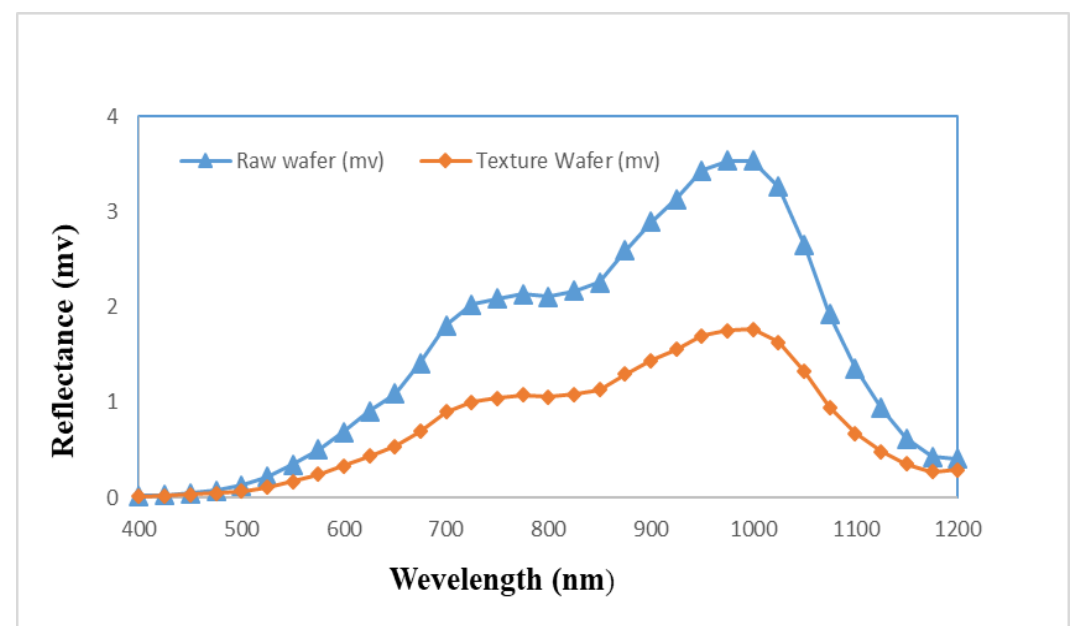

Figure 1. Reflectance of raw wafer and textured wafer for different periods of time as a function of wavelength

\section{Scanning Electron Microscope (SEM)}

The scanning electron microscope has been performed on the surface to study the surface morphology before cleaning and texturing process.

\section{Effect of Cleaning Process}

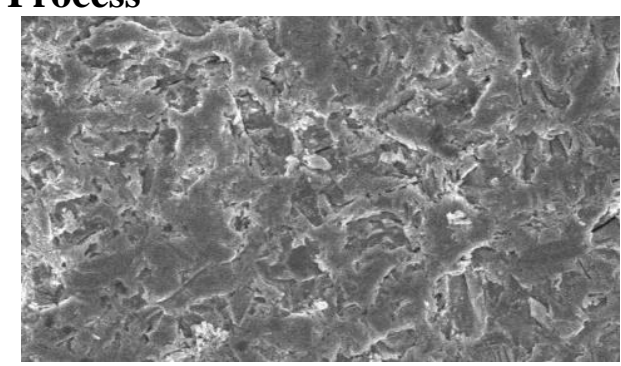

Figure 2. SEM microphotograph (5000 times magnification) of clean surface silicon wafer

Figure 2 shows the Scanning Electron Microscope (SEM) image of the saw-damage surface silicon wafer, which is removed and cleaned.

\section{Effect of Texturing of Silicon Wafer}

The topography of the textured surface after drying in compressed air is investigated using scanning electron microscopes (SEM). Figure 3 shows the SEM image of the textured surface at different magnifications. 


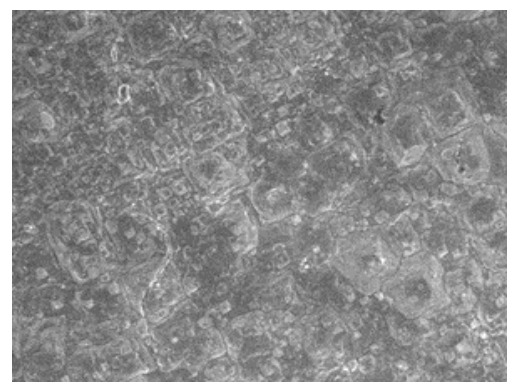

2000 times magnification

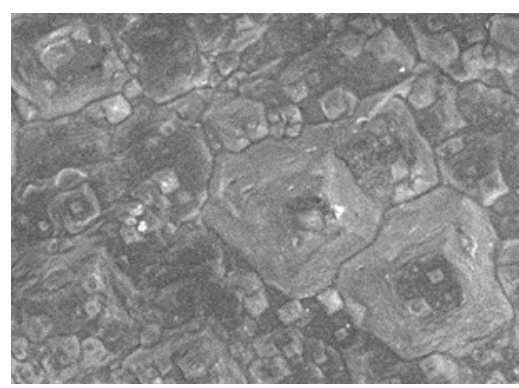

5000 times magnification

Figure 3. SEM microphotograph of textured surface wafer

From these images, it can be seen that alkaline texturing processes are pyramid-like structures that are formed on the surface of the silicon wafer. These structures can provide a foundation for the front surface light trapping. The results of light trapping are also verified using the surface reflectance data, which is shown in Figure 1.

\section{Sheet Resistance Method}

Sheet resistance of the silicon wafer was measured by a four point probe measurement system. The sheet resistance is important during the fabrication of monocrystalline silicon solar cell. Sheet resistance indicates whether diffusion of phosphorus is properly done or not.

In this study, the sheet resistance is measured using raw silicon wafer and after the phosphorus doping into the p-type silicon wafer. From the measurements, it is observed that the average sheet resistances for the raw wafer are $2.3 \Omega-\mathrm{cm}$ which is within the limit of sheet resistance of $1-3 \Omega-\mathrm{cm}$. The result indicates that the diffusion can take place in the fabricated wafer.

The average sheet resistances of the diffused wafer are $0.80 \Omega-\mathrm{cm}$ which are compatible with the high efficiency solar cells. Recent studies have shown better results in terms of efficiency with the shallow emitter junction whose sheet resistance was within the range of 50-100 $\Omega$ /square (Hilali, 2006; Yelundur, 2005). From the diffused wafer measurement, it is observed that the sheet resistance value at different locations is very close to each other. This indicates that the wafers are uniformly doped in the process. The sheet resistance results of diffused wafers show that monocrystalline silicon wafers are doped by phosphorous atoms properly and uniformly.

\section{Surface Photovoltage Method}

The surface photovoltage (SPV) is a method which determines the diffusion length of a minority carrier and lifetime of semiconductors, and the minority carriers defines the behavior of the $\mathrm{p}-\mathrm{n}$ junction of a semiconductor. Figure 4 plots the SPV response from the front surfaces. The SPV technique 
utilizes the change of the electrochemical potential in the space-charge region of a semiconductor during excess carrier generation due to illumination of the sample with light of the suitable wavelength and intensity (Stangl, 2009). In this study, the value of minority carrier diffusion length is shown using mini monochromator, which is driven with a stepper motor to vary wavelengths in $\sim 400-1200 \mathrm{~nm}$ spectral range with flux $(\Phi) 10^{13}$ to $10^{14} \mathrm{~cm}^{-2} \mathrm{~s}^{-1}$. It also uses a Stanford Research 510 lock-in amplifier. The reciprocal of the normalized surface (SPV) is plotted against the penetration depth of $\alpha^{-1}$ ( $\alpha$ light absorption coefficient). According to Leong et al., the spectral dependence of the penetration depth is obtained by:

$$
\alpha^{-1}=\left(83.18 \times 10^{3} \lambda^{-1}-74.87\right)^{-2}
$$

and $\mathrm{SPV}^{-1}$ plotted against $\alpha^{-1}$ shows a linear trend whose negative intercept with $\alpha^{-1}$ axis. This gives the value of minority carrier diffusion length (L) (Castaldini, 2000).

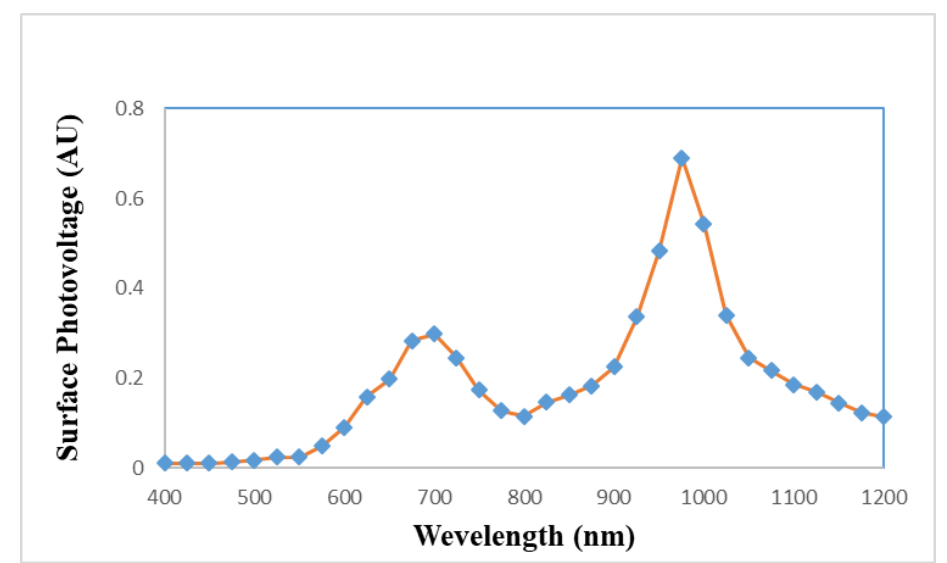

Figure 4. Surface photovoltage of diffused wafer for different periods of time as a function of wavelength

From Figure 4, the wavelength of $700 \mathrm{~nm}$ to $750 \mathrm{~nm}$ is smaller than the range of $975 \mathrm{~nm}$ to $1025 \mathrm{~nm}$. Within the range of $700 \mathrm{~nm}$ to $750 \mathrm{~nm}$, the photons are absorbed in the emitter region. Electrons in the emitter region are a majority carrier and have low injection condition. The Fermi level of the electron does not change from the equilibrium position. Thus, no photo generated from the electron diffuses to the surface (Suhail, 2012). 


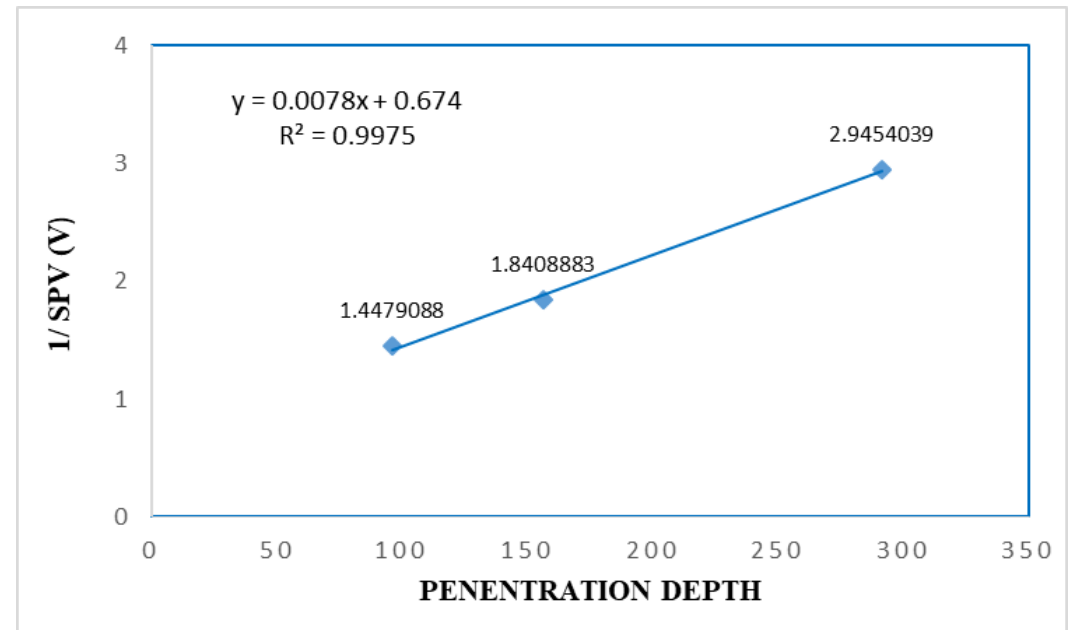

Figure 5. Reciprocal of the normalized $\mathrm{SPV}^{-1}$ plotted against Penetration depth $\left(\alpha^{-1}\right)$

In the wavelength between $975 \mathrm{~nm}$ and $1025 \mathrm{~nm}$, photo generated electrons that are produced in the junction and in the base close to the junction will diffuse to the surface. The quality of the emitter is measured by the increase in the number of electrons reaching the surface. The number of electrons collected at the surface increases in a region of $975 \mathrm{~nm}$ to $1025 \mathrm{~nm}$. Therefore, using the wavelength $975 \mathrm{~nm}$ to $1025 \mathrm{~nm}$ determines the minority carrier diffusion length and lifetime. In Figure 4 and 5, the value of $\mathrm{L}$ is determined by calculating the $\mathrm{x}$ value of $\mathrm{y}=0$. From the linear curve, the values of $\mathrm{L}$ are $86.4 \mu \mathrm{m}$ and the minority carrier lifetime becomes $2.8 \mu \mathrm{sec}$, where the minority carrier diffusivity of silicon solar cell is $27 \mathrm{~cm}^{2} \mathrm{~s}^{-1}$.

\section{Conclusion}

This paper focused on examining the characterization of texturing and the diffusion of monocrystalline Si wafers. Through characterization process, it was observed that the textured wafer formed a pyramid structure and the reflectance of the textured wafer at $1,000 \mathrm{~nm}$ wavelength is $1.7659 \mathrm{mV}$, which is smaller than $1.6142 \mathrm{mV}$ of the raw wafer. After diffusion with $\mathrm{POCl}_{3}, \mathrm{~N}$ type is formed on the P-type material and average sheet resistance of $0.80 \Omega$ $\mathrm{cm}$ is obtained. In SPV characterization, it is observed that the minority carrier diffusion length is $86.4 \mu \mathrm{m}$ and the lifetime of the electrons of the solar cell is $2.8 \mu$ second. Nonetheless, further investigation can be carried out in the future.

\section{References:}

1. Chen, J., Sekiguchi, T., Yang, D., Yin, F., Kido, K., \& Tsurekawa, S. Phys. Rev. B 63, 115209 (2001) 
2. Castaldini, A., Cavalcoli, D., Cavallini, A., \& Rossi, M. (2000). Surface photovoltage analysis of crystalline silicon for photovoltaic applications. V. 72 P. (559-569) Y.

3. Elghitani, H. \& Martinuzzi, S. (1989). J. Appl. Phys. 66, 1723 http://www.ucep.gatech.edu/papers/21epvsec/2CV.5.54.pdf. (Access September 2015)

4. Hilali, M. M., Nakayashiki, K., Ebong, A., \& Rohatgi, A. (2006). Prog. Photovolt: Res. Appl., V. 14, P. 135-144, Y. https://www.academia.edu/6065192/Analysis_and_Simulation_of_Di ffusion_Process_to_Improve_Efficiency_of_Silicon_Solar_Cell_for_ Concentrator_Photovoltaic_Application. (Access September 2015) http://www.pveducation.org/pvcdrom/pn-junction/diffusion-length (Access October 2015).

5. Iftiquar, S.M., Lee, Y., Ju, M., Balaji, N., Dhungel, S.K., \& Yi, J. "Fabrication of Crystalline Silicon Solar Cell with Emitter Diffusion, SiNx Surface Passivation and Screen Printing of Electrode", "Photodiodes - From Fundamentals to Applications", ISBN 978-95351- 0895-5.

6. Leong, C.S., Amin, N., Sualiman, M.Y., Zaharim, A., Sopian, K. \& Zaidi, S.H. "Some Key Issues in the Processing and Fabrication of Higher Efficiencies Silicon Solar Cells", Proceedings of the 3rd WSEAS International Conference on Renewable Energy Source, pp.305.

7. Muller, H.J., Fuke, C., Kreßner-Kiel, D., \& W"urzner, S. (2011). Energy Procedia 3, 5

8. Narayanan, S. \& Wohlgemuth, J. (1994). Prog. Photovolt. 9, 129

9. Salahuddin, Q. (2017). Chapter 2 - Fundamentals of Standalone Photovoltaic Systems, Standalone Photovoltaic (PV) Systems for Disaster Relief and Remote Areas, Pages 31-82, https://doi.org/10.1016/B978-0-12-803022-6.00002-2

10. Suhaila, S., Cheow, S.L., Sulaiman, M.Y., Sopian, K., \& Saleem, H.Z. (2013). Fabrication and Characterization of Al-BSF Bifacial Solar Cell. Conference Record of the IEEE Photovoltaic Specialists Conference. DOI: 10.1109/PVSC.2013.6745021

11. Stangl, R. (2009). "Specific Characterization Method, Surface Photovoltage". Silicon Photovoltaic, pp.1-3

12. Suhail, S., Sulaiman, M.Y., Saleem, H.Z., \& Sopian, K. (2012). Surface passivation studies o $n+p p+$ Bifacial Solar Cell. International Journal of Photoenergy. Volume 2012: Article ID 278764

13. Yelundur, V., Nakayashiki, K., Hilali, M., \& Rohatgi, A. (2005). Proceedings of IEEE Photovoltaic Specialists Conference, P. 959-962, Y. 